\title{
PARTISIPASI MASYARAKAT LOKAL DALAM PENGEMBANGAN KAWASAN WISATA GEOPARK BATUR DI KINTAMANI KABUPATEN BANGLI
}

\author{
I Gede Wiramatika \\ Universitas Udayana \\ E-mail: wiramatika93@gmail.com \\ I Nyoman Sunarta \\ Universitas Udayana \\ E-mail: nyoman_sunarta@unud.ac.id \\ I Putu Anom \\ Universitas Udayana \\ E-mail: anompariwisata@gmail.com
}

\begin{abstract}
This study aims to examine the participation of local communities in the development of the Batur Geopark tourist area in Kintamani, Bangli Regency regarding the participation of local communities in the development of the Batur Geopark tourist area, the obstacles faced by local communities in the development of the Batur Geopark tourist area, and the efforts made by the Government in developing the tourist area Batur Geopark. In this study the data collected through interviews, observations, literature studies, documentation studies, and the Community then analyzed the data using qualitative descriptive data analysis techniques. The presentation of data analysis in this study was carried out qualitatively through verbal delivery with interpretative descriptive techniques. The results of this study indicate that in the development of the Batur Geopark tourist area there are still several obstacles faced in its development. The government's efforts in developing the Batur Geopark tourist area are: the formation of a tourism awareness group, tightening permits for facility construction, establishing a management agency, procuring tourism facilities, improving the road infrastructure, structuring material excavation at the foot of Mount Batur, holding promotions, and providing tourism training. The forms of community participation in the development of the Batur Geopark tourist area are: preserving the biodiversity of flora and fauna, building tourism facilities, developing the typical Kintamani major culinary, cultural preservation, taking jobs in the tourism sector, nature conservation, and the formation of security officers.
\end{abstract}

Keywords: Community Participation, Tourism Development, Geopark 


\section{Pendahuluan}

Pengembangan pariwisata yang merupakan salah satu bagian dari pembangunan ekonomi. Dalam meningkatkan pertumbuhan ekonomi dalam suatu negara, sehingga dapat menciptakan lapangan kerja bagi masyarakat luas yang nantinya dapat meningkatkan pendapatan masyarakat. Secara keseluruhan pada akhirnya dapat meningkatkan kesejahtraan masyarakat. Tujuan yang ingin dicapai dalam melakukan pengembangan kawasan pariwisata dalam hal ini adalah untuk meningkatkan kunjungan wisatawan ke suatu daerah yang akan dikembangkan yang nantinya dapat memberikan kepuasan kepada wisatawan yang berkunjung (James, 1987). Pengembangan pariwisata yang dapat mendorong perekonomian dari masyarakat di suatu daerah tertentu. Sebagai hal yang teroenting adalah kesiapan dalam setiap sektor baik fasilitas maupun infrastruktur dibandingkan dengan sektor lainnya. Erawan, 1994 menyatakan bahwa pariwisata merupakan suatu sektor dari pulau Bali semenjak dua puluh tahun terakhir ini pariwisata dapat memberikan dampak yang sangat baik terhadap pertumbuhan ekonomi masyarakat Bali.

Bali yang merupakan salah satu provinsi yang menjadi salah satu destinasi pariwisata yang terkenan dengan keindahan alam, keberagaman dan keunikan kebudayaan-kebudayaan yang ada di masing-masing daerah, Bali juga terkenal dengan keramah-tamahan penduduknya yang menjadikan Bali terkenal baik di nusantara maupun ke mancanegara. Sebagai salah satu destinasi yang berskala internasional dengan keindahan alam da keunikan dari budaya-budaya yang ada, melalui sektor pariwisata masyarakat Bali sendiri terus berupaya menjaga kelestarian alam, budaya dan yang tak kalah pentingnya adalah meingkatkan kualitas pelayanan yang diberikan kepada wisatawan yang berkunjung sehingga wisatawan dapat lebih lama menghabiskan waktu kunjungannya dan dapat meningkatkan jumlah kunjungan wisatawan. 
Pembangunan pariwisata secara berkelanjutan, melalui pengelolaan sumber alam, dan lingkungan hidup dalam hal pendayagunaan agar tetap mempertimbangkan keseimbangan dan kelestarian lingkungan alam yang ada di sekitar daerah pembangunan pariwisata. Pembangunan pariwisata yang secara berkelanjutan dapat memberikan manfaat bagi suatu pembangunan dan kesejahteraan masyarakat dan lingkungan alam yang ada.

Kabupaten Bangli adalah salah satu kabupaten yang ada di provinsi Bali. Bangli yang sangat akan potensi pariwisata yang menjadi salah satu daerah kunjungan wisatawan. Bangli yang memiliki daya tarik wisata yang terkenal dengan daya tarik wisata alam, dan kebudayaan-kebudayan yang ada disekitaran masyarakat yang sudah dikenal baik dalam lingkup nusantara bahkan sampai ke lingkup mancanegara. Salah satu daerah pariwisata yang ada di kabupate bangle adalah kawasan pariwisata Kintamani. Kintamani yang merupakan salah satu kawasan pariwisata yang terkenal dengan keindahan alam pegunungan Gunung Batur, Danau Batur dan keunikan budaya-budaya yang ada di masing-masing daerah yang ada dikintamani dan yng tak kalah menariknya adalah Geopark Batur yang kini menjadi daya Tarik Wisata dengan Kawasan Kaldera Batur yang sangat indah dan menarik untuk dinikmati yang keindahannya sudah diakui sebagai warisan budaya dunia dengan dibentuknya Batur Global geopark.

Batur Global Geopark adalah daya tarik wisata baru yang berbasis alam. Kehadiran Batur Global Geopark yang memperkasa daya Tarik wisata Bali yang dikenal didominasi dengan seni budaya termasuk keramahtamahan penduduk. Sidang Global Geoparks Network yang dilakukan pada tahun 2012 yang bertempat di Portugal yang telah menetapkan Gunung Batur sebagai Global Geoparks dengan geopark pertama yang ada di Indonesia. Geopark atau yang disebut juga Taman Bumi yang merupakan suatu kawasan atau situs warisan geologi (geological heritages) yang 
mempunyai nilai-nilai ekologi dan warisan budaya (cultural heritages) yang memiliki fungsi sebagai daerah konservasi, edukasi dan sustainable development.

Partisipasi masyarakat dalam tahap pengembangan pariwisata di destinasi pariwisata yang dapat menentukan suatu keberhasilan dari destinasi pariwisata (Pitana, 1999). Penetapan Batur sebagai anggota Global Geopark Network ternyata tidak berdampak terhadap peningkatan pendapatan dan taraf hidup masyarakat lokal. Sebelum dilakukannnya implementasi, perencanaan, merupakan hal utama yang dapat dilakukan oleh seluruh pengampu kepentingan dan stakeholder. Hal tersebut dikarenakan kurangnya partisipasi langsung masyarakat dalam kegiatan yang direncanakan pemerintah setempat dan kurangnya keterlibatan masyarakat dalam pengambilan keputusan.

Melihat kondisi tersebut, dari sebelum dan sesudah ditetapkannya Batur Global Geopark yang tidak adanya perubahan taraf hidup masyarakat lokal setempat, maka diperlukannya pengembangan kawasan wisata Geopark Batur secara berkelanjutan yang mengacu pada peran serta masyarakat lokal, dimana dengan konsep Pariwisata Berbasis Masyarakat sebagai pedoman untuk tetap menjaga keberlanjutan dari Kawasan Wisata Geopark Batur.

\section{Landasan Teori}

Teori Doxey's (1975) Irritation Index

Teori ini akan dipergunakan untuk melihat bagaimana masyarakat menanggapi tentang kegiatan kepariwisataan guna mempormulasikan factor yang berpengaruh terhadap redahnya partisipasi masyarakat lokal dalam pengembangan kawasan wisata. Teori ini dipergunakan untuk melihat seperti apa masyarakat menanggapi tentang kepariwisataan guna memformulasikan upaya-upaya untuk mengemas Kawasan Wisata Geopark Batur. Terdapat 4 kategori bagaimana 110 JUMPA Volume 8, Nomor 1, Juli 2021 
penjelasan seperti: Euphoria (Perasaan bangga rohani dan jasmani), Aphaty (sikap acuh tak acuh), Annoyance (sikap terganggu /terusik), dan Antagonism / xenophobia (rasa benci / pertentangan). Teori Doxey's ini digunakan untuk mengkaji respon masyarakat terhadap partisipasi masyarakat lokal dalam pengembangan Kawasan Wisata Geopark Batur di Kintamani Kabupaten Bangli.

Arnstein's (1969) A Ladder of Citizen Participation

Teori ini banyak diadopsi dalam bentuk partisipasi masyarakat baik dalam Pretty (1995) maupun Tosun (2000). Hakekat dari teori ini adalah membagi bentuk partisipasi masyarakat dalam 8 bentuk seperti: Therapy, Informing, Consulation, Placation, Partnership, Delegated Power, dan Citizen Control. Kedelapan bentuk ini akan memperlibatkan sejauh mana partisipasi dari masyarakat di Kawasan Wisata Geopark Batur dalam pengambangan pariwisata.

\section{Kerangka Berpikir}

Penelitian ini berfokus untuk meganalisis hambatan yang dihadapi masyarakat lokal, Upaya-upaya Pemerintah untuk memaksimalkan Partisipasi masyarakat lokal, partisipasi masyarakat lokal dalam pengembangan Kawasan wisata Geopark Batur, digunakan analisis data kualitatif dengan landasan teori Teori Doxey's Irritation Index dan Teori Arnstein's (1969) A Ladder of Citizen Participation dengan konsep-konsep Konsep parisipasi Masyarakat, Pariwisata Berbasis Masyarakat, Pemberdayaan Masyarakat, Tahap Pengembangan Pariwisata, dan Geopark. Setelah mendapatkan sebuah hasil penelitian, selanjutnya akan ditarik simpulan penelitian yang kemudian akan menimbulkan beberapa rekomendasi atau saran bagi pemerintah daerah, Badan Pengelola masyarakat lokal yang ada Kintamani. 


\section{Metode Penelitian}

Penelitian ini merupakan penelitian kualitatif dengan lokasi penelitian di kawasan wisata Geopark Batur, Kawasan Geopark yang dimaksud dalam penelitian ini adalah kawasan Bukit Payang Gunung Batur di Kintaman Kabupaten Bangli. Intrumen penelitian ini yang digunakan untuk mengumpulkan data yang berupa panduan wawancara yang berisikan panduan dan pedoman wawancara untuk mendapatkan data yang mendalam dar masyarakat, pengelola, dan Pemerintah dan panduan pengamatan yang digunakan dalam melakukan observasi dilapangan.

Pengumpulan data dalam penelitian ini menggunakan teknik wawancara kepada Kepala Dinas Pariwisata Kabupaten Bangli, BKSDA (Balai Konservasi Sumber Daya Alam), BUGG (Batur Unesco Global Geopark), Pengusaha Industri Pariwisata, Tokoh Masyarakat, dan Masyarakat observasi dilakukan di sekitaran lokas penelitian, studi kepustakaan, dan studi dokumentasi dilakukan di lokasi penelitian dengan tujuan untuk mmperoleh data yang akurat. Informan dalam penelitian ini ditentukan dengan menggunakan Informan kunci (key informan) yang merukana orang-orang yang dianggap mengetahui mengenai objek penelitian.

Teknik analisis data dalam penelitian ini menggunakan teknik analisis data deskriptif kualitatif. Dengan teknik analisis data menggunakan analisis deskriptif kualitatif, dengan menjabarkan data-data yang diperoleh dalam bentuk uraian. Penyajian analisis data dalam penelitian ini disajikan secara kualitatif yang diinterpretasikan mengacu pada konsep dan teori serta kerangka pemikiran.

\section{Hasil dan Pembahasan}

\section{Hambatan Dalam Pengembangan Kawasan Wisata Geopark Batur}

Kawasan wisata Geopark Batur yang sudah dikembangkan mulai tahun 2012 lalu. Potensi wisata yang ada disekitaran kawasan Geopark Batur yang sangat 
beragam. Kawasan wisata Geopark Batur yang sudah terkenal di dalam negeri bahkan sampai keluar negeri, akan tetapi dalam pengembangan kawasan wisata Geopark Batur belum dapat dikembangkan secara optimal, yang disebabkan karena adanya beberapa hambatan yang dihadapi oleh pemerintah dan badan pengelola dan masyarakat. Dalam memecahan hambatan yang dihadapi pada sekarang ini harus melibatkan Pemerintah, dan semua pengampu kepentingan. Pihak-pihak yang harus duduk bersama dalam mengatasi semua kendala atupun hambatan mengenai pengembangan kawasan wisata Geopark Batur, seperti: Pemerintah, Badan Pengelola, masyarakat lokal, para pemangku kepentingan. Adapun hambatan yang dihadapi dalam pengembangan di kawasan wisata Geopark Batur, yaitu:

\section{Kurangnya Komitmen Pemerintah Dalam Menjalankan Sebuah Program}

Dari keadaan yang dapat dilihat pada sekarang ini di kawasan Kintamani komitmen pemerintah masih sangat kurang mulai dari penataan obyek wisata, pembangunan, pembangunan fasilitas, sarana prasarana yang masih sangat kurang seperti lampu penerangan jalan yang sudah lama dan tidak berfungsi, tidak adanya toilet umum untuk wisatawan dan kurangnya papan-papan informasi mengenai kawasan pariwisata kintamani.

2. Sikap Masyarakat Sebagai Tuan Rumah (Host) Belum Sadar Terhadap Keberadaan Geopark

Kesadaran masyarakat dalam pengembangan pariwisata sangat penting dalam pengembangan kawasan pariwisata kedepan. Namun, pada kenyataannya masyarakat yang ada disekitaran Kintamani kurang sadar terhadap perkembangan pariwisata yang ada, masih banyak masyarakat yang ditemui tidak paham mengenai apa itu Geopark, yang diketahui masyarakat Geopark itu adalah kawasan disekitaran Gunung Batur dan banyak masyarakat masih acuh tak acuh terhadap kawasan Geopark yang ada di daerahnya. 
3. Belum Ada Posisi Dan Peranan Masyarakat Secara Jelas Dalam Pengelolaan Pariwisata

Posisi dan peranan masyarakat lokal yang ada disekitaran Kintamani pada sekarang ini masih belum diberikan ruang dan posisi-posisi khusus dalam sebuah perencanaan pengembangan kawasan Geopark yang menyebabkan banyaknya masyarakat tidak memahami apa itu Geopark yang ada didaerahnya. Keberdaan masyarakat Kintamani sampai sekarang ini masih sebagai penikmat dari pengembangan pariwisata sekarang.

4. Kualitas SDM pariwisata masih rendah

Kendala berikutnya yang harus mendapatkan perhatian yang lebih serius didalam pengembangan kawasan wisata Geopark Batur adalah Sumber Daya Manusia. Dari pengembangan pariwisata yang ada akan menyebabkan proses terjadinya interaksi antara wisatawan yang sedang berkunjung dengan masyaakat lokal.

5. Banyak Pengusaha Hotel Dan Restoran Yang Melanggar Kawasan Lindung

Aktivitas pembangunan di Kawasan Wisata Geopark Batur yang semakin tidak terkendali. Bangunan-bangunan tersebut menutupi pemandangan Gunung Batur, Danau Batur dan Kaldera Baturnya. Banyak bangunan yang ada di sepadan jalur hijau yang ada di Kintamani yang tidak mengantongi ijin pembangunan. Pembangunanpembangunan yang dilakukan disamping menutupi pemandangan juda sangat berdampak pada kerusakan lingkungan yang disebabkan oleh limbah-limbah hasil produksi. 


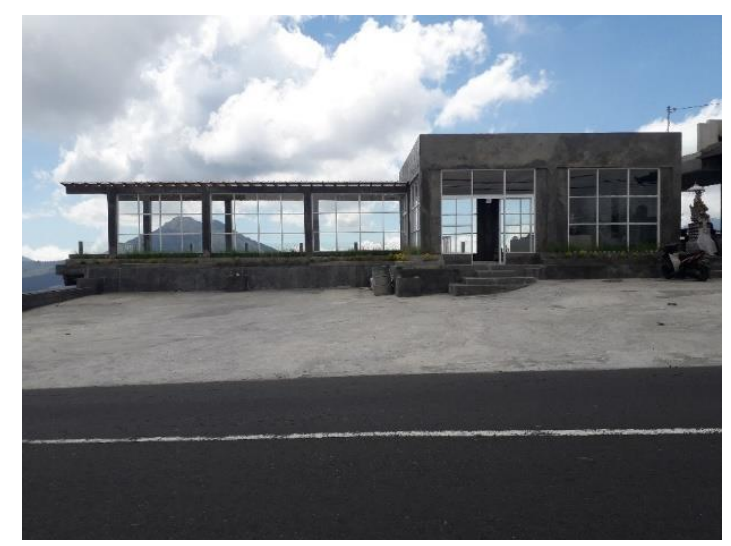

Gambar 1. Pembanguan Fasilitas Pariwisata Yang Menutupi Panorama Gunung Batur Sumber: dokumentasi penelitian, 2021

6. Rusaknya Infrastruktur Jalan

Jalan-jalan yang ada di Kintamani pada saat ini kondisinya masih sangat kurang baik yang diakibatkan oleh adanya galian C. Mobil Truk yang bermuatan pasir dan Batu belum memiliki jalur khusus yang nenyebabkan jalur-jalur yang ada di Kintamani cepat mengalami kerusakan dan bahkan mengganggu perjalan wisatwan yang sedang berkunjung ke Kintamani karena harus melintas di jalan yang masih dilalui oleh Truk pembawa material.

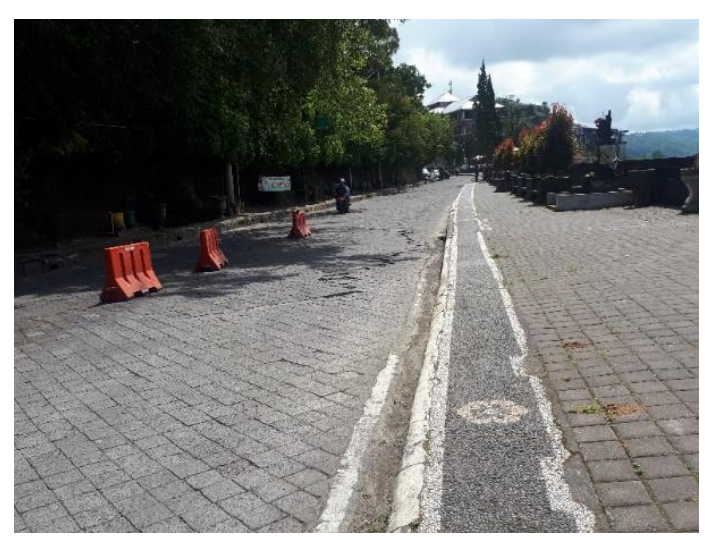

Gambar 2. Kondisi Jalan Rusak di Kawasan Wisata Geopark Batur Sumber: dokumentasi penelitian, 2021 


\section{Upaya Pemerintah Dalam Pengembangan Kawasan Wisata Geopark Batur}

Kabupaaten Bangli merupakan daerah yang terkenal dengan keberadaan kawasan wisata Geopark Batur didalamnya yang memiliki keindahan panorama Gunung Batur, Danau Batur dan keberadaan kalderanya serta potensi-potensi wisata lainnya yang memiliki keindahan.

Pengembangan kawasan wisata Geopark tidak dapat dipisahkan dari peran serta stakeholder (pemerintah) dalam hal ini pemerintah daerah Kabupaten Bangli yang menjadi fasililator dan memfasilitasi segala sesuatu di dalam mendukung pengembangan kawasan wisata Geopark Batur dalam pembangunan kawasan wisata dengan cara melakukan pendampingan kepada masyarakat. Peran pemerintah jug sebagai kordinator. Sebagai pemerintah dapat menentukan kebijakan dan menentukan strategi dalam pembangunan kawasan wisata Geopark. Selain menjadi fasilitas dan kordinator pemerintah juga menjadi motivator dalam pembangunan pariwisata peran pemerintah.

Sebagai motivator diperlukan agar pelaku-pelaku usaha pariwisata yang ada di Kintamani terus berinovasi dan terus melakukan pengembangan pariwisata. Upaya pemerintah dalam pengembangan kawasan wisata Geopark Batur adalah sebagai berikut:

\section{Pembentukan Kelompok Sadar Wisata (Pokdarwis)}

Pembentukan Pokdarwis yang ada di kawasan wisata Geopark Batur mampu menggambarkan partisipasi masyarakat secara penuh dalam pengeloaan potensi wisata dikawasan wisata Geopark Batur. Dengan adanya kesadaran tentang peran kelompok sadar wisata (Pokdarwis) dalam kelangsungan kegiatan-kegiatan kepariwisataan yang ada, maka pemerintah akan lebih mudah menyampaikan program-program kepariwisataan. Beberapa hal yang sudah dilakukan pemerintah dalam peningkatan peran serta dan partisipasi masyarakat dalam peningkatan peran 
serta dan partisipasi masyarakat dalam kelompok sadar wisata (Pokdarwis) antara lain seperti, lomba kelompok sadar wisat, pembinaan dan penyuluhan kelompok sadar wisata, pelatihan SDM pariwisata di tingkat kelompok sadar wisata (Pokdarwis) dan lain sebagainya.

2. Mengetatkan Perijinan Bagi Pembangunan Fasilitas Pariwisata

Untuk mengatasi kendala pelanggaran pembangunan dikawasan lindung, dalam sebuah pembangunan, perijinan sangat penting untuk dilakukan karena dengan adanya sebuah ijin dalam melakukan pembangunan fasilitas-fasilitas pendukung pariwisata yang ada di Kintamani pemerintah dapat mengetahui layak dan tidak layaknya sebuah fasilitas untuk dibangun. Penegasan perijinan pembangunan di sepadan jalan yang ada dikintamani perlu di ketatkan karena untuk menjaga kelestarian lingkungan alam agar tetap bisa dinikmati oleh wisatawan dari kendaraan mereki. (Hasil wawancara bersama Ida Bagus Giri Putra, Kantor Bupati Bangli, 17 Maret 2021).

\section{Pembentukan Badan Pengelola}

Badan Pengeloala Pariwisata Batur Unesco Global Geopark yang berkantor di museum Geopark Penelokan Desa Batur Selatan, Kecamatan Kintamani. Pengelolaan kawasan Geopark Batur mengikut sertakan desa-desa di kawasan inti untuk ikut berperanserta dalam proses perencanaan, pengembangan, pengeloaan dan memonitoring proses pengembangan kawasan wisata Geopark. Pembentukan badan pengelola ini sudah direncanakan sejak 2010 yang lalu namun pembentukan tersebut baru terwujud pada januari 2019.

\section{Pengadaan Fasilitas Kepariwisataan}

Dalam hal ini pemerintah Kabupaten Bangli sangat mendukung dan memfasilitasi di dalam pengadaan-pengadaan fasilitas pendukung kepariwisataan di kawasan wisata Geopark Batur. Adapun fasilitas kepariwisataan yang dilakukan oleh 
pemerintah Kabupaten Bangli, yaitu: Papan-papan Petunjuk, Penyediaan Papanpapan Informasi, Pengadaan Penerangan Jalan

5. Perbaikan Prasarana Jalan

Salah satu akses yang mempermudah wisatawan untuk datang ke kawasan wisata Geopark Batur adalah prasarana jalan. Kondisi-konsisi jalan yang ada dan jalan yang menuju kawasan wisata Geopark Batur masih perlu mendapatkan perhatian pemerintah untuk dilakukannya perbaikan terhadap jalan-jalan yang mengalami kerusakan. Sarana jalan yang menjadi salah satu faktor yang mempermudah wisatawan untuk mengakses kawasan wisata Geopark Batur dengan rasa tenang dan nyaman.

6. Pengetatan Penggalian Material di Kaki Gunung Batur

Dinas kebudayaan dan Pariwisata Kabupaten Bangli yang bekerjasama dengan kasi koprasi ketertiban umum dalam menyikapi hal tersebut yang juga harus bekerja sama dengan pemerintah Provinsi Bali karena Galian C yang merupakan kewenangan Provinsi atas perizijan dan pembebasan hal milik dari masyarakat setempat dan terus memperhatikan serta menjaga kelestarian lingkungan di Kaldera Batur, sehingga kerusakan yang diakibatkan oleh aktivitas pertambangan galian C bisa diminimalisir dengan terus dilakukannya pengawasan dilokasi yang beroptensi menjadi lahan galian $\mathrm{C}$ dan lokasi yang sudah menjadi lokasi galian $\mathrm{C}$ terhadap aktivitas pertambangan galian $C$ agar kegiatan tersebut dapat di pantau, di minimalisir secara perlahan di dalam pengembangan kawasan wisata Geopark Batur. 


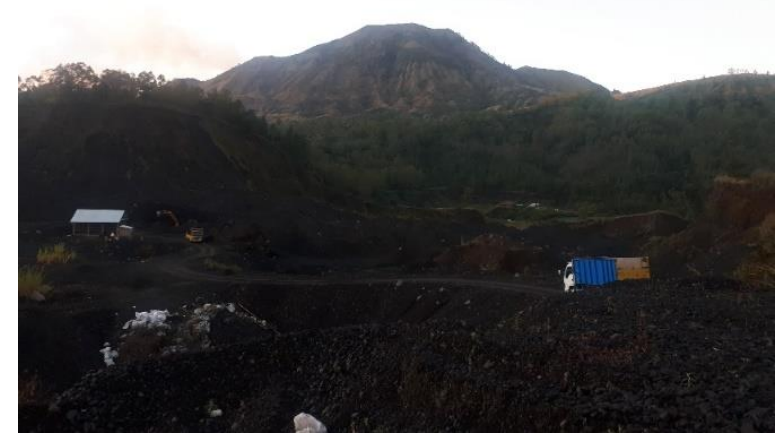

Gambar 3. Aktivitas Galian C

Sumber: dokumentasi penelitian, 2021

\section{Mengadakan Promosi}

Untuk mengatasi kendala promosi dan memperkenalkan suatu produk pariwisata yang ada di kawasan wisata Geopark adalah dengan cara promosi yang efekif. Kawasan wisata Geopark Batur merupakan produk wisata yang perlu diperkenalkan secara luas, bahkan sampai ke tingkat Internasional. Dengan dikenalnya kawasan wisata Geopark dapat memberikan pilihan tersendiri bagi wisatawan yang datang kembali. Promosi yang paling penting dilakukan saat ini adalah menggencarkan penerapan CHSE yang merupakan penerapan protokol kesehatan yang berbasis Cleanliness, healt, safety, environment sustainability sehingga wisatwan tertarik untuk berkunjung ke kawasan wisata Geopaark Batur di tengah pandemic covid-19 dengan penerapan CHSE tersebut akan memberikan sebuah rasa amam bagi wisatawan yang berkunjung.

\section{Pengadaan Pelatihan Kepariwisataan}

Kendala sumber daya manusia (SDM) pada kawasan wisata Geopark Batur sangat menjadi perhatian serius oleh Pemerintah Kabupaten Bangli. Program yang dilakukan dalam mengatasi permasalahan tersebut dengan mengadakan pelatihan kepariwisataan. Kurangnya pemahaman masyarakat terhadap pariwisata 
menyebabkan kendala dalam bidang sumber daya manusia (SDM). Dengan pelatihann tersebut masyarakat lokal diharapkan mampu memahami tentang unsurunsur kepariwisataan, mampu mengelola pariwisata dan mampu mengambangkan pariwisata yang ada, sehingga kepariwisataan yang ada di Kintamani bisa berkembang dan memberikan manfaat positif bagi masyarakat dan dalam pengembangannnya tetap memperhatikan ketestaian alam dan budaya yang ada.

\section{Partisipasi Masyarakat Lokal Dalam Pengembangan Kawasan Wisata Geopark Batur}

Kawasan pariwisata yang ada di dalam Geopark Batur yang memiliki beberapa obyek wisata baik dalam maupun buatan yang memiliki keunikan tersendiri. Objek wisata yang ada di kawasan wisata Geopark Batur yang menjadi daya tarik unggulan yaitu seperti Kaldera Gunung dan danau Batur, Penelokan Trunyan dan kawasan kintamani. Kawasan ini sudah sangat terkenal bagi para wisatawan nusantara. Kintamani sebagai kawasan Geopark yang menyebabkan keberadaan perkembangan pariwisata Kintamani semakin mengalami perkembangan.

Pendekatan pembangunan yang menekankan pada keberadaan dan partisipasi masyarakat lokal harus mulai di ikutsertakan dalam proses pengembangan kepariwisataan. Pendekatan ini harus mampu menilai dan mengembangkan pengetahuan dan meningkatkan keterampilan masyarakat di bidang pariwisata serta melakukan perombakan dalam seluruh praktek dan pemikiran di dalam melakukan pembangunan.

Partisipasi masyarakat lokal Kintamani di dalam pengembangan kawasan wisata Geopark Batur sangat berperan besar dan sangat aktif. Melihat partisipasi masyarakat yang sangat aktif sehingga perlu di dilakukannya pembinaanpembinaan, pemahaman-pemahaman tentang Geopark, dan pelatihan mengenai kepariwisataan itu sendiri. 
Kintamani yang sudah ditetapkan sebagai anggota dari Global Geopark Network yang tidak dapat terpisah dari peran aktif masyarakat yang mendukung partisipasi dari masyarakat lokal itu sendiri secara pnuh di dalam melakukan konservasi kawasan Kintamani sehingga dapat memenuhi tujuan dan ditetapkannya Kintamani sebagai kawasan wisata Geopark Batur. Adapun beberapa partisipasi masyarakat lokal yang ada di Kintamani, yaitu:

\section{Menjaga Kelestrian Hayati Flora dan Fauna (Endemic)}

Di kawasan wisata Geopark Batur terdapat berbagai macam keragaman Hayati yang cukup besar baik yang ada di kawasan Geopark maupun di luar kawasan Geopark. Flora yang berkembang di Kintamani yang sudah dikenal sampai ke mancanegara, jenis-jenis tanaman yang dilestarikan yaitu seperti: kopi arabika, jeruk kintamani. Tanaman-tanaman tersebut dapat kita jumpai dengan sangat mudah di perkebunan-perkebunan yang digarap oleh masyarakat yang berkecimpung sebagai petani. Adapun jenis fauna atau satwa yang menjadi ciri khas dari Kintamani yaitu seperti: ikan mujair dan anjing kintamani. Pelestarian ikan mujair yang dilakukan oleh masyarakat Kintamani yang bertempat di kawasan Danau Batur dengan membangun kuramba-kuramba pengembangbiakan ikan mujair sehingga keberadaan ikan mujair tidak mengalami kepunahan.

\section{Pengadaan Failitas-Fasilitas Pariwisata}

Fasilitas pariwisata merupakan salah satu faktor penting di dalam menunjang tumbuh kembangnya kawasan wisata Geopark Batur. Keberadaan Kintamani yang kini belum dikuasai oleh banyak investor keberadaan fasilitas-fasilitas pariwisata yang ada di kawasan wisata Geopark Batur sudah sangat memadai danlam menunjang tumbuh kembangnya kawasan wisata Geopark Batur. Fasilitas pariwisata yang ada di kawasan Geopark Batur yang dimiliki oleh masyarakat-masyarakat lokal yang memiliki banyak modal untuk menyediakan fasilitas-fasilitas pariwisata dalam mendukung perkembangan kawasan wisata Geopark Batur. 


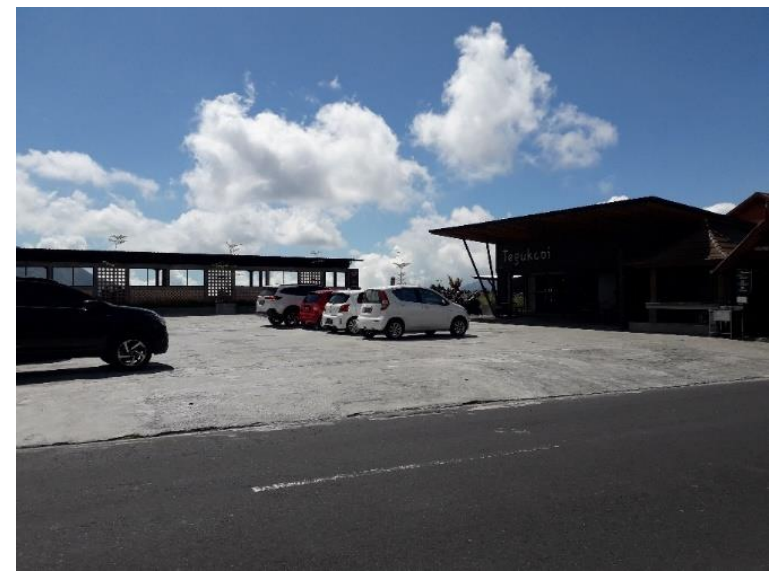

Gambar 4. Salah Satu Fasilitas Pariwisata Yang Ada di Kintamani Sumber: dokumentasi penelitian, 2021

\section{Pengembangan Kuliner Mujair Nyat-nyat Khas Kintamani}

Salah satu kuliner yang sedang berkembang adalah kuliner mujair nyat-nyat yang ada di Kintamani. Ikan mujair merupakan ikan yang berasal dari Danau Batur, yang menjadi salah satu kuliner yang harus dinikmati oleh wisatawan yang sedang berkunjung ke kawasan wisata Geopark Batur. Ikan mujair yang menjadi ciri khas dari kawasan wisata Geopark Batur, kini menjadi peluang bisnis bagi masyarakat lokal untuk membuka sebuah usaha.

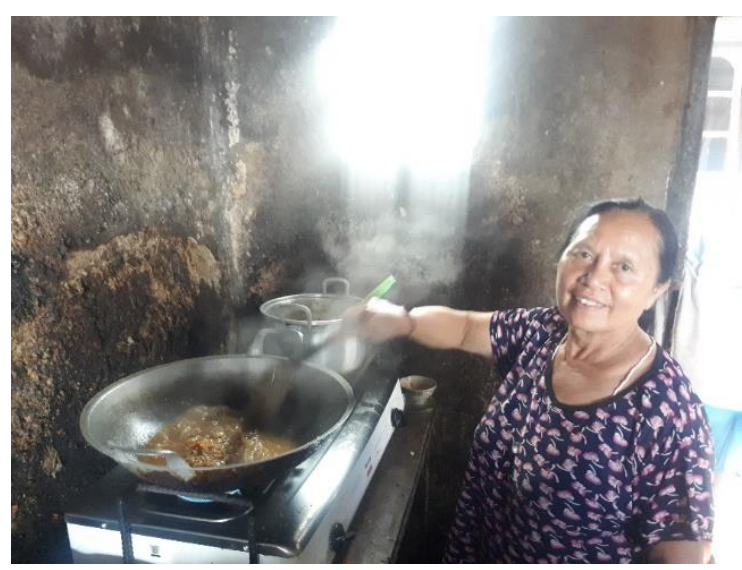

Gambar 5. Penggitan Bisnis Mujair Nyat-nyat

Sumber: dokumentasi penelitian, 2021 


\section{Menjaga Kelestarian Budaya}

Seni budaya masyarakat Kintamani yang diwariskan oleh para leluhur mereka yang sangat beragam, seiring dengen berkembangnya kawasan wisata Geopark Batur masyarakat kembali ingin membangkitkan seni budaya yang mereka miliki. Untuk mewujudkan dan melestarikan budaya-budaya tersebut dilaksanakannya langkah nyata dengan menggali potensi-potensi pada setiap daerah di kawasan Kintamani. Seni budaya yang dimiliki oleh masyarakat Kintamani seperti bermacam-macam taritarian yang ada dari masing-masing daerah, cara penguburan ari-ari yang digantung di pohon bukal, penguburan mayat yang diletakkan di bawah pohon kemenyan dan lain sebagainya.

\section{Mengambil Pekerjaan di Bidang Pariwisata}

Dengan mamanfaatkan perkembangan pariwisata masyaraat lokal yang ada dikawasan Kintamani mulai berkecimpung ke dalam dunia pariwisata. Keberadaan fasilitas-fasilitas pariwisata yang ada di Kintamani yaitu seperti Hotel, Restaurant, Coffee Shop dan lain sebagainya yang membuka lapangan pekerjaan bagi masyarakat lokal. Masyarakat-masyarakat lokal Kintamani sebagian besar berkecimpung ke dalam dunia pariwisata selain menjadi karyawann dari fasilitas-fasilitas yang ada masyarakat juga sebagai pemilik tempat wisata serta sebagai lokal guide untuk memberikan informasi mengenai keberadaan obyek-obyek wisata yang ada di Kintamani.

\section{Menjaga Kelestarian Alam}

Masyarakat Kintamani didalam menjaga kelestarian hutan dengan cara bekerjasama dengan dinas-dinas terkait seperti: Dinas Perkebunan, Dinas Pertanian, Kebudayan dan Pariwisata, BKSDA, dan komponen-komponen masyarakat, seperti: perguruan tinggi, pencinta alam, LSM dan sebagainya untuk melakukan penanaman

bibit-bibit pohon di kawasan Kintamani yang merupakan realisasi dari visi Danu 
Kerthi, upaya nyata untuk menjaga kesucian dan kelestarian sumber-sumber air, seperti: sungai, mata air dan Danau serta Wana Kerthi, menjaga kesucian dan kelestarian hutan-hutan yang ada dikawasan Geopark.

\section{Pembentukan Petugas Keamanan}

Keamanan merupakan faktor penting yang harus ditingkatkan dalam pengembangan kawasan wisata Geopark Batur, karena dengan keamanan maka wisatawan yang sedang berkunjung akan mendapatkan ketenangan dan rasa aman. Pada setiap daerah yang ada di kawasan wisata Geopark Batur yang memiliki kelompok keamanan yang bernama pecalang melibatkan partisipasi masyarakat yang masuk dalam organisasi pecalang dari masing-masing desa yang akan membuat peran aktif masyarakat dalam menjaga keamanan kawasan wisata Geopark Batur. Pecalang-pecalang yang disiapkan akan berkordinasi di dalam menjaga, mengontrol dan mengamankan mulai dari pihak-pihak pendatang yang masuk Kintamani, keamanan pada tiap-tiap daya tarik wisata yang ada di kawasan Geopark Batur.

\section{Simpulan dan Saran}

Dalam pengembangan kawasan wisata Geopark Batur yang belum dapat dilaksanakan secara optimal karena masih ditemuinya beberapa hambatan atau kendala yang harus diselesaikan dalam pengembangan kawasan wisata Geopark Batur kedepan. Dalam pengembangan kawasan wisata Geopark Batur yang tidak dapat dipisahkan dari upaya dan peran aktif stakeholder yang dalam hal ini adalah pemerintah Kabupaten Bangli. Pemerintah Kabupaten Bangli yang diharapkan berupaya dan berperan aktif dalam pengembangan kawasan wisata Geopark Batur, sehingga dapat mengatasi hambatan yang ada dalam penataan dan pengembangan Geopark Batur. Partisipasi masyarakat Kintamani sangat besar di dalam mendukung pengembangan kawasan wisata Geopark Batur. Kawasan ini yang merupakan 
kawasan konservasi semenjak ditetapkannya kaldera Batur sebagai Geopark. Kawasan kaldera Batur yang sangat dijaga kelestariannya yaitu Gunung Batur dan Danau Batur serta lingkungan alam sekitar. Kawasan wisata Geopark Batur yang terdiri dari dari tarik wisata baik wisata budaya, alam dan buatan yang memiliki keunikan tersendiri. Hal inilah yang menyebakan budaya dan alam yang ada di Kawasan wisata Geopark Batur masih terpelihara dengan baik kelestarian dan keasriannya. Keberadaan partisipasi masyarakat dalam pengembangan kawasan wisata Geopark Batur yang sangan berberan dalam aktif didalam mendukung pengembangan kawasan wisata Geopark.

Saran pertama masyarakat agar tetap menjaga kelesatarian alam, budaya yang ada di kawasan wisata Geopark Batur melalui peningkatan partisipasi masyarakat lokal dalam meningkatkan kunjungan wisatawan yang nantinya akan memberikan dampak ekomoni kepada masyarakat itu sendiri, kedua kesadaran masyarakat yang perlu ditingkatkan lagi melalui pelatihan-pelatihan yang berkaitan dengan pariwisata, karena dengan kesadaran masyarakat akan pentingnya pariwisata maka pengembangan kawasan wisata Geopark Batur akan lebih memudahkan pelaksanaannya, ketiga pembangunan-pembangunan fasilitas pariwisata yang ada di kawasan wisata Geopark Batur diharapkan tetap memperhatikan kelestarian lingkungan alam dan tidak merusak pemandangan Gunung Batur, Danau Batur dan kaldera Batur, keempat dengan adanya pertambangan galian $\mathrm{C}$ yang masih dilakukan secara terus menerus oleh masyarakat di kawasan wisata Geopark Batur, dalam hal ini Pemerintah diharapkan untuk meningkatkan peraturan di wilayah yang berpotensi menjadi lokasi pertambangan agar tidak terjadinya perluasan lokasi pertambangan.

\section{Ucapan Terimakasih}

Puji syukur kami panjatkan kehadirat Tuhan Yang Maha Esa, karena atas berkat dan rahmat-Nya penulis dapat menyelesaikan artikel ini dapat terselesaikan 
dengan baik dan tepat waktu. Ucapan terimakasih penulis juga ucapkan kepada Prof. Dr. dr. A.A. Raka Sudewi, Sp.S (K). selaku Rektor Universitas Udayana yang sudah memberikan kesempatan dan fasilitas kepada saya untuk mengikuti perkuliahan Program Magister di Universitas Udayana, Dr. Drs. Nyoman Sunarta, M.Si. dan Dr. Drs. I Putu Anom, M.Par. selaku pembimbing dalam penulisan artikel, Seluruh Bapak Ibu dosen dan pegawai Magister Pariwisata Universitas Udayana yang telah membantu dala peyelesaian artikel Jro Lingsir dan Ni Made Nariani selaku orang tua dan adik saya I Kadek Litawan yang selalu memberikan dukungan dan Ni Putu Emy Leona Parhilla sebagai orang yang terkasih yang sudah selalu mendukung saya, memberikan motivasi, memberikan saran, memberikan semangat dan selalu setia menemani saya dalam pengumpulan data penyusunan artkel ini. Penulis tetap berharap semoga artikel ini dapat bermanfaat tak hanya untuk penulis saja namun juga bermanfaat untuk pengembangan kawasan wisata Geopark Batur kedepannya. Demikian artikel ini saya susun, bila ada kesalahan dalam penyusunan laporan artikel ini saya mohon maaf.

\section{Daftar Pustaka}

Anonim. UNESCO. United Nations Educational, Scientific and Cultural Organization Arnstein, Sherry R, 169. A Ladder of Citizen Participation. American Institude of Planners, Vol. 35, No. 4, pp. 216-224.

Bumin, Burham. 2003. Analisis Data Penelitian Kualitatif. Jakarta: PT. Raja Drapindo Persada.

Doxey, G. 1975. A Causation Theory of Visitor-resident Irritants. Methodology and Research Inferences Travel and Tourism Research Associations Sixth Annual Conference. San Diego.

Ibrahim. 2015. Metodologi Penelitian Kualitatif. Bandung: Alfabeta.

Pitana I Gede, Gayatri Putu G. 2005. Sosyologi Pariwisata, Yogjakarta: ANDY.

Pitana I Gede. 1999. “Community Management dalam Pembangunanan Pariwisata". Majalah analisis Pariwisata Vol. 2. No. 2.

126 JUMPA Volume 8, Nomor 1, Juli 2021 
Sally Asker, Louise Boronyak, Naomi Carrard and Michael Paddon. 2010. Effective Community Based Tourism. Sydney. Sustainable Tourism Coopetative Research Center.

Spllane James J. Dr. (1987). Ekonomi Pariwisata, Sejarah dan Prospeknya. Yogyakarta: Kanisius.

Sukma, Rohman. 2019. Perencanan pariwisata dan Keberlanjutan Lingkungan. Denpasar: Cakra Media Utama.

Sunarta I N, Sukma Arida I N, Saptono Nugroho, Adikampana I Made, Luh Gede Leli Kusuma Dewi and Yohanes Kristianto. 2020. UNESCO Global Park Batur Development: A Psychographic Approach. Palarch's Journal of Archaeology of Egypt/Egyptology, ISSN 1567-214x.

Wardianta, M. Hum. 2006. Metode penelitian pariwisata, yogyakarta: CV Andi Offet.

\section{Profil Penulis}

I Gede Wiramatika, S.Par. adalah mahasiswa Magister Pariwisata, Universitas Udayana, Bali. Saya menyelesaikan program sarjana di Fakultas Pariwisata Universitas Udayana Pada tahun 2018, program Magister Pariwisata di Universitas Udayana tahun 2021. Selain kuliah saya juga aktif di salah satu organisasi Kelompok Sadar Wisata (Pokdarwis) dalam meningkatkan pengembangan pariwisata yang ada di Desa saya, Desa Batur Kintamani, Bangli, Bali.

Dr. Drs. I Nyoman Sunarta, M.Si. selaku pembimbing I yang merupakan Dekan dari Fakultas Pariwisata Universitas Udayana, serta aktif mengajar pada program S1 Pariwisata, S2 Pariwisata, dan S3 Pariwisata, universitas Udayana, terutama dalam Mata Kuliah Geografi Pariwisata dan Pariwisata yang berbasis alam dan berwawasan lingkungan.

Dr. Drs. I Putu Anom, M.Par. selaku pembimbing II yang merupakan mahasiswa angkatan pertama program Magister Pariwisata di Universitas Udayana dan merupakan Dosen dari Fakultas Pariwisata Universitas Udayana. 